\title{
Current trends in the IT services market
}

\author{
Vera Krasavina ${ }^{1, *}$ \\ ${ }^{1}$ Peoples' Friendship University of Russia (RUDN University), Mikluho-Maklaya St., 6, Moscow, \\ 117198, Russia
}

\begin{abstract}
Relevance. Today, in the context of global digitalization, the world IT services market is developing at quite a rapid pace and remains one of the fastest growing segments of the IT industry. Researchers of this market in their works describe direct dependence between globalization of IT services market and development of national economic systems. Thus, today it is most important to determine the key trends in the development of IT services world market. In this paper, the most important trends of the most significant segments of IT service market are determined and described, such as: IT consulting, system integration, custom software development, IT outsourcing, IT support, and IT education and training. Understanding and following the current trends contributes not only to the development of existing opportunities for companies' growth, but also to the emergence of new ones, due to which the companies will not only retain, but also increase their competitive advantages on the global market. Goal. To identify and analyze the most important current trends in the global IT service market development, which contribute not only to the reformation of the market itself, but also to change in the relationship of its constituent elements. To systemize the latest trends in the global IT service market and evaluate them in terms of their impact on the economic development of the countries. Methodology. The methodology of system analysis, methods of structural, logical and comparative analysis are used in this paper. Results. The key trends in the development of the main segments of the modern IT service market have been determined and described. Among them, cloud computing technologies, cybersecurity and innovative business models are particularly important. Conclusions. It is obvious that the identified trends in the development of the global IT services market are critical to the effective performance of each enterprise both in terms of understanding, forming a business strategy, timely implementation of innovative business models, following the latest trends, and in terms of building up their competitive advantages in extremely difficult conditions on the global market.
\end{abstract}

\section{Introduction}

The information technology industry is growing year by year. One of its most important components - the IT services market - is dynamically developing and penetrates many areas of our life. Demand for IT services is growing. The pace of IT services distribution is

\footnotetext{
*Corresponding author: krasavina_va@rudn.ru
} 
increasing year after year. More and more countries become active players on the IT services market. In this regard, both scientists-analysts and business representatives treat this matter with great attention. At the same time, a great number of various national and regional programs for the development of this industry is being developed. All this determines relevance of the topic of this paper and points at the need to identify and consider the key tendencies in the development of IT services market.

As the basis for the structure of the IT services market, discussed in this paper, we will take market segmentation developed in the framework of IDC methodology [2]. IDC divides the IT services market into six basic segments shown in Table 1.

Table1. Structure of IT services market.

\begin{tabular}{|l|l|}
\hline \multirow{3}{*}{ Project-oriented } & IT services \\
\cline { 2 - 2 } & IT Consulting \\
\cline { 2 - 2 } & System integration \\
\cline { 2 - 2 } Outsourcing-oriented & Developing custom-made software \\
\hline \multirow{2}{*}{ Support and training-oriented } & IT outsourcing \\
\hline & IT support \\
\cline { 2 - 2 } & IT education and training \\
\hline
\end{tabular}

\subsection{IT-consulting}

Consider each segment of the market separately. First, we turn to the IT consulting market. According to Gartner, this segment of the market was $\$ 180$ billion in 2018, demonstrating a $2.5 \%$ average annual growth rate. Since its inception, the consulting industry has been constantly undergoing structural changes. With intensification of the digitalization, consulting industry faced the need to reformate: today new business models are required, new areas and growth targets, innovative products and services are demanded. The IT consulting industry employs a large number of employable people. The companies operating in this segment are among the largest employers in the world, making a significant contribution to both economic growth and the well-being of the population. The IT industry is rapidly developing and implementing the latest digital technologies, which today represent the latest platforms for innovation and business growth. This necessitates understanding of the current strategic trends on the IT consulting market.

The consulting and IT services industry is becoming more and more global (see table 2). This makes it possible to identify the first major trend - globalization of the IT consulting market. IBM revenue calculated by the segments of Global Business Services and Technology Services and Cloud Platforms. DXC Technology is an American IT company created in 2017 based on the combined assets of Computer Sciences Corporation and HPE Enterprise Services, corporate Services Division of Hewlett Packard Enterprise. The revenue for DXC Technologies in fiscal year 2018 was calculated with consideration of HPE revenue and in 2017 - without it.

The largest consulting firms in a number of developed countries, such as the United States, France, Canada and some developing countries such as India, including Accenture, Tata Consultancy Services Limited, Cognizant, NTT Data, etc. show growth of up to $20 \%$ per year (see table 2).

Today, the industry is at the stage where there is a clear differentiation between fastgrowing companies and their competitors. We can witness market consolidation - this is the second significant trend. To overcome the balance on the market and increase competitiveness, some medium- and small business consulting firms (MSB) are considering innovative business models. If the new models are successful, they could 
"remake" both the nearly 100-year consulting industry and the 50-year history of IT services.

Table 2. TOP-10 companies-providers of IT services (rating of companies compiled by Everest Group company (Everest Group, 2019), revenue data taken from the official data of the respective companies)

\begin{tabular}{|c|c|c|c|c|c|}
\hline Rating & $\begin{array}{c}\text { Company } \\
\text { (headquarters) }\end{array}$ & $\begin{array}{c}\text { Revenue } \\
\text { for } 2018\end{array}$ & $\begin{array}{c}\text { Revenue for } \\
2017\end{array}$ & $\begin{array}{c}\text { Dynamics, } \\
\%\end{array}$ & $\begin{array}{c}\text { Number of } \\
\text { employees } \\
\text { at the end } \\
\text { of 2018 } \\
\text { (thousands) }\end{array}$ \\
\hline 1 & Accenture (Ireland) & 39.6 & 34.9 & 13.2 & 477 \\
\hline 2 & $\begin{array}{c}\text { Tata Consultancy } \\
\text { Services Limited (TCS) } \\
\text { (India) }\end{array}$ & 19.09 & 17.58 & 8.6 & 395 \\
\hline 3 & Cognizant (USA) & 16.13 & 14.81 & 8.9 & 282 \\
\hline 4 & Wipro (India) & 8.4 & 7.7 & 9.1 & 165 \\
\hline 5 & $\begin{array}{c}\text { HCL Technologies } \\
\text { (India) }\end{array}$ & 7.84 & 6.97 & 12.5 & 116 \\
\hline 6 & Capgemini (France) & 14.89 & 14.13 & 5.4 & 211 \\
\hline 7 & IBM (USA) & 51.279 & 50.625 & 1.3 & 351 \\
\hline 8 & Infosys (India) & 10.939 & 10.208 & 7.2 & 226 \\
\hline 9 & $\begin{array}{c}\text { DXC Technologies } \\
\text { (USA) }\end{array}$ & 24.556 & 7.607 & 222.8 & 150 \\
\hline 10 & NTT Data (Japan) & 19.102 & 15.998 & 19.4 & 118 \\
\hline
\end{tabular}

Recently, a growing number of large consulting companies have been forming strategic alliances with IT service providers. At the same time, many large IT companies are actively creating consulting teams. The range of provided services is becoming very similar, allowing us to identify another trend: homogeneity of consulting and IT service providers.

Today, a number of large multinational companies (MNCs) are in stagnation attempting to balance their short-term quarterly forecasts with the desire for long-term growth. CEOs of these companies are trying to please the shareholders, which leads to a loss of focus and degradation of strategic vision. By comparison, several Indian companies, such as Wipro, Infosys, LTI, Mphasis, etc., providing IT services, are actively expanding and hiring highly skilled professionals, thus, increasing their attractiveness for customers. These serviceproviders pose a serious threat not only to multinational corporations, but to elite consulting companies, including the "big four 4"( the four largest companies providing auditing and consulting services: Deloitte, E Ernst \& Young (EY), KPMG и PricewaterhouseCoopers $(\mathrm{PwC})$ ). This trend can be described as "MNCs against Indian companies." The influence of Indian companies on the IT market hard to overestimate - eight companies in the top 20 IT service providers are of Indian origin [3].

\subsection{System integration}

Moving on to system integration, the next segment of the IT services market, we note that one of the largest researching and consulting companies Gartner does not identify system integration as a separate service, in contrast to IDC company. Development and integration of complex IT solutions for enterprise automation (basis for system integration) should follow current trends which can provide worthy opportunities for the future of companies. The first tendency is the strategy of mobile platforms. Today businesses need increasingly flexible integration solutions that easily incorporate conventional mobile platforms into outdated application architecture. The second significant trend is holistic integration. 
System integration is usually limited to new or flexible applications and sometimes does not pay enough attention to the familiar and sometimes outdated software or local databases. Today, however, any company, for example, fully operating in the cloud, must have the possibility to manage its infrastructure based on multiple types of applications (such as using cloud software and local databases). That's why system integrators are more and more focusing on integration platforms that serve different types of applications. After all, this holistic approach becomes not only desirable and relevant, but also necessary.

Social technologies as part of infrastructure are the third trend on the system integration market. Today, social platforms are the key component in various business units, but they only function as information warehouses that cannot share data with other areas of business. System integrators will have to include social platforms as part of their overall system integration. It should be noted that most system integrators continue to follow this developing trend.

Finally, the fourth trend is mobile applications. More than 10 years ago, Apple company introduced iOS based on applications, the first popular app-based operating system, and this has led to a paradigm shift in both the consumer and business market. Companies are taking advantage of this new model of applications as iOS and Android popularity is growing in many spheres. System integrators understand that corporate applications, operating on these platforms, will need to be integrated in a larger business architecture.

\subsection{Custom Software Development}

The wave of digital transformation that will reformat businesses around the world has a big impact on how technology teams think of custom software development (SD), the third core segment of the IT services market. We identify the key technological trends that shape the custom software industry. The first tendency in this segment is the growing popularity of open source technologies. A decade ago, there would have been only a few companies willing to use software with open source. Today, there are less than $3 \%$ of companies around the world without using any form of open source software in their technology stack [7]. Technological giants, such as Google, Facebook, Microsoft, use open source software to launch their most important systems. They also significantly contribute to the support and growth of the developer communities around these technologies with open source. Businesses need to follow the latest technological requirements, therefore, this trend in the development of custom software should certainly be the priority.

Today, artificial intelligence (AI) is the major component of almost every digital platform: from e-commerce to movie streaming. Companies are developing machine learning capabilities to learn more about their users and automatically improve their software experience. Artificial intelligence-based chatbots serve the needs of billions of people online, and companies invest big sums to make these bots smarter by the minute. For software developers it is important to be able to write the code, which can be well integrated with self-learning algorithms, so that using this code in corporate applications could be the most beneficial for businesses. And this determines the second significant trend in the bespoken software development sector - readiness of the software to introduce artificial intelligence.

Today, the world's largest companies keep their technology cores in the cloud. Cloud computing, from platforms to infrastructure, has changed the way businesses use software. According to the report [4] of IDG company, already more than $73 \%$ of the enterprises in the world have at least one application or part of their computing infrastructure in the cloud, and $17 \%$ plan to do this within a year. From becoming more flexible in terms of applied engineering to saving money by eliminating local infrastructure costs, enterprises redefine their business vision in the digital era. The advantages are evident: scalability on demand, 
global availability, the best providers in every niche of cloud service, etc. Thus, we have come to the third key trend - cloud technologies (see Pic.1) - this is another trend that every company should take seriously to improve its ROI (return on investment ratio, this is a coefficient which shows profitability or loss of an investment, in other words coefficient of return on investment) for technological investments.

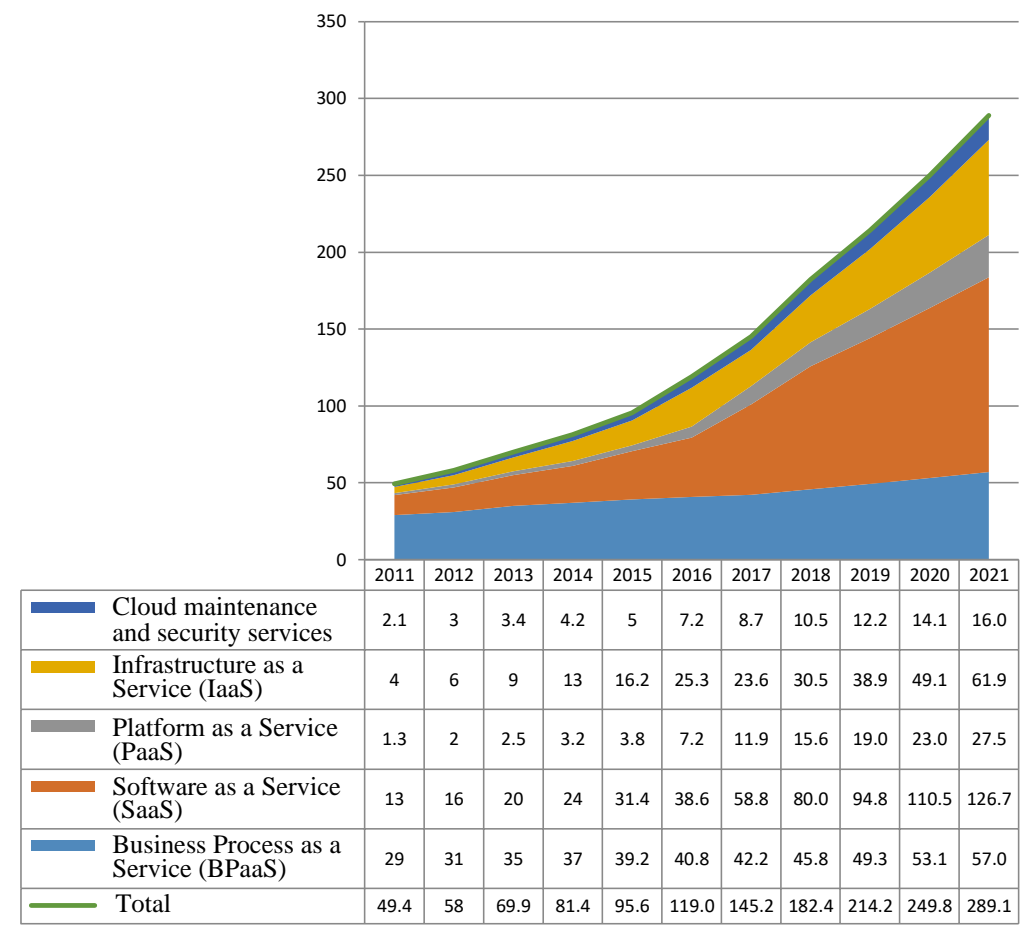

Fig. 1. Global revenue of public cloud services.

Currently, cybercrime [1] is the biggest threat to any company in the world and one of the biggest problems of humanity. It has a huge impact on society. According to the forecasts of Cybersecurity Ventures [1] cybercrime will cause $\$ 6$ trillion in damage a year by 2021 , while in 2015 the damage was $\$ 3$ trillion. Today cloud computing boom and transition from local software development to rich Internet-applications not only provide better digital opportunities for business but create grounds for various kinds of software vulnerability. Rich Internet application (from Eng. RIA) is a web-application accessible via the Internet, saturated with functionality of desktop applications, which is provided either by unique browser specifics, either through a plugin or by "sandbox" (virtual machine). It used to be common to transfer software development services to only one provider. However, if a project requires multiple technology stacks, it will be safer and more reliable for the company to collaborate with several providers. This tendency of using several providers has already shaped and will only intensify in the coming years. According to Veracode report [9] devoted to software vulnerabilities, more than $85 \%$ of all software have at least one vulnerability, and more than $13 \%$ can lead to seriously critical failures. Security issues must be considered even for the smallest applications. Conclusion: custom software security is the most important trend in the development of global IT services market in the segment of custom software development [11].

\subsection{IT outsourcing}


Today, IT services market presents a great number of IT outsourcing providers. These are leading companies, such as ZS, Synoptek, Infosys, Wipro, Capgemini, etc., which offer reasonable prices and a wide range of technical proposals. And since many companies prefer IT outsourcing, it is not surprising that this trend is constantly changing and developing. Consider the main areas of this development.

India, China and the Philippines remain the key areas for providing external IT services. However, today the countries of Central and Eastern Europe, such as Hungary, Poland, Russia, Ukraine, Romania, etc. are gradually catching up Asian suppliers, i.e. we can witness a change in the main outsourcing areas.

Both customers and IT service providers expect new contact models to be used - another trend. This will help make IT outsourcing more interpersonal and financially beneficial. According to the GSA [8] report, new contracts will be based on actual results rather than quantitative indicators. Contracts will be concluded with IT services providers as with service integrators who share risks and responsibilities. Manual process automation is one of the main trends in IT outsourcing that is likely to lead to a revolution in the future. Virtual agents and bots used to optimize routine tasks will give a powerful boost to all industries. Huge investments will go into robotic process automation (RPA, Robotic process automation) and artificial intellect. Transition to automation models will be compulsory for all IT outsourcing providers who want to survive in the conditions of fierce competition and satisfy all needs of their customers [10].

\subsection{IT support}

IT infrastructure of enterprises is rapidly changing. Traditional server racks are steadily disappearing as more and more companies are moving some or even all their IT services to the "clouds". By 2020 LogicMonitor predicts [5] that $83 \%$ of the enterprise workload will be in the cloud. With cloud technologies companies get more opportunities than ever, so it is relevant to identify the today trends of this market.

Companies that want to avoid total dependency on one provider or take advantage of the best offers made by different providers, take so-called multi-cloud approach - this is the first significant trend in the IT support sector. Multi-cloud approach means using more than one cloud provider to store your data and other services. According to RightScale report [6] for 2018, the multi-cloud environment is now the preferred strategy for most businesses: $84 \%$ of organizations use several cloud service providers.

Next trend is the use of serverless architecture (also called "function as a service" or FaaS, function-as-a-service) - a method of software development allows applications to be placed on third-party services. FaaS refers to a category of cloud services which provides a platform for developing and running applications without any burden related to IT supporting infrastructure. It is important to consider that, in fact, virtual servers cannot be ignored under any conditions. That means that we are talking not about abandoning the "iron" but about a new approach to providing services.

While some companies plan to go all-in and migrate completely to the cloud, others prefer a hybrid approach which means that companies simultaneously use public and private clouds, as well as traditional local equipment. So, we have come to another trend: using hybrid clouds. According to the RightScale survey [6], 58\% of businesses use hybrid strategies. Often companies use this approach to store confidential data or critically important IT services within the company because of concerns about security, performance or opaque cost on a monthly subscription for cloud services.

The era of dealing with cybersecurity threats only when they have arisen is likely to come to an end. Preventive measures time is coming. In this way, we can outline the 
next important trend: emergence of DevSecOps strategy. This strategy allows to shorten the life cycle of system development to quickly provide new functions, corrections and update in close relevance with business aims. Currently developers take a step further with DevSecOps (development security operations) which allows paying greater attention to security issues. Applying values of DevOps to software security means that security verification becomes an active, integral part of the development process. Developers solve real security problems before they occur, not after a threat or leak has already occurred - all this without slowing down the production cycle.

No department is as vital to the entire company as the IT department. While most departments are responsible only for their own efficiency, the IT department ultimately is responsible for the efficiency of the entire enterprise. It has two key areas: tools and procedures. The IT department must use both effectively and focus on performance. To achieve this, it should use "correct" software and have a developed support platform.

Many IT support organizations trying to improve efficiency turn to best practices, such as ITIL, which provide guidance on how IT services should develop and maintain software. However, there is a significant risk to get stuck in endless processes, paperwork and deployment of heavy technologies aimed at implementing support. An IT support service must be able to balance between strict standards, leading methods and the need to provide quality services to the customers right away. Thus, we have identified a trend combination of strict procedures and flexibility.

For many employees, social networks (such as Facebook and Twitter) are the backbone of their personal experience in the Internet. Considering the reliance on these platforms, companies turn to similar social media corporate tools (such as Yammer), to facilitate collaboration among the departments. This is another trend in the IT support segment. Corporate tools today allow to improve performance of the IT department and the entire company as well.

For example, if it took a week to coordinate a process, now the result can be reached in a matter of hours by interviewing users or creating a small task team to discuss the problem.

\subsection{IT education and trainings}

For decades, it has generally been a full-time training in classrooms with a teacher. The use of computers, including distance education services, also existed on this market, but to a much smaller extent. Face-to-face education is characterized by the issuance of certificates, which IT professionals take very seriously, trying to keep them relevant. However, with the development of new technologies and digitalization, virtual education has been gaining increasing popularity which has formed a trend of transition from face-to-face learning to virtual education.

Virtual learning (webinars) has some advantages. First, there have been developed coeducational tools combining both interactivity and face-to-face learning. Secondly, virtual learning offers a much more flexible schedule that attracts more and more people. Thirdly, distance education excludes transport costs for students. Fourthly, the cost of such training is lower than that of a full-time one. Altogether it motivates constant increase in the demand for this service in this form.

Today, digital technologies change so fast that IT professionals have constantly to update their skills. In this regard, modern technical areas such as cloud computing, cybersecurity, big data, software development, DevOps, etc. require the availability of modern IT departments for continuous professional and local training. Nowadays, some companies still require certificates from the specialists. However, today, digital education is becoming increasingly important and popular. In its turn it forms the next significant trend on IT education and training market - emergence of digital and mixed learning. Digital 
learning meets the needs of IT professionals in broad and in-depth knowledge and skills that require frequent renewal. At the same time, production costs for video courses are steadily declining, creating a trend of growing number of providers who provide only digital education services.

As a result of these shifts on the IT education market, offerings that combine real-time learning with digital learning materials are becoming increasingly important. Virtual courses provide a space for deep focus, immersion in the topic and the ability to learn from the teacher, while digital learning offers flexibility, timely updates and the ability to learn practical skills. Mixed learning models enable learners to acquire basic skills or gain indepth knowledge of technology, providing flexibility and access to the latest information.

\section{Conclusion}

It is obvious that companies providing different kinds of IT services have interesting and impressive future, given how markedly the market has grown in recent years, how rapidly the modern IT environment is changing. The IT service market is growing and developing, various kinds of services and models of IT services are spreading, consumer demand is growing and, as the consequence, the genuine interest of researchers to the industry is growing, too. With a high degree of probability, it can be argued that even in the countries where the IT services market emerged relatively recently, soon it will become full value and fully formed due to the fast stabilization pace of the world IT services industry. In the context of global digitalization, the identified trends open new opportunities for development and sustainable growth of companies, gaining popularity on the IT services market. At the same time, it should be noted that current trends also require a new level of knowledge, innovation, tools and business models. Therefore, in order to benefit from all the advantages and opportunities that the new trends provide, experts should carefully and consistently implement the full range of technological innovations and models.

\section{References}

1. Cybersecurity Ventures, db 2019 Official Annual Cybercrime Report, (2019).

2. EITO, ICT Market Report 2018/19 - Definitions \& Methodology (2018).

3. Everest Group. IT Service Provider of the Year (2019).

4. IDG, 2018. Cloud Computing Survey (2018).

5. LogicMonitor. Cloud Vision 2020: The Future of the Cloud Study (2017).

6. RightScale, 2018. State of the Cloud Report. (2018).

7. J. Steven, Vaughan-Nichols, db It's an open-source world: 78 percent of companies run open-source software. https://www.zdnet.com/article/its-an-open-source-world-78percent-of-companies-run-open-source-software/

8. The Global Sourcing Association (GSA), Outsourcing Yearbook (2016).

9. Veracode. State of Software Security 9, (2018).

10. V.A. Krasavina, A.Y. Kormilicziyn, Innovations in Creation and Management of Business. Moscow (2018). .

11. V.M. Matushok, V.A. Krasavina, National Interests: Priorities and Security 11, 19882004 (2017). 